\title{
Innovation Ecosystem Analysis 1986-2017: A Citation-Based Literature Survey
}

\author{
Yangyi Meng, Yutong Ma \\ School of Business Administration, South China University of Technology, Guangzhou, China \\ Email: yangyi-meng@foxmail.com
}

How to cite this paper: Meng, Y.Y. and Ma, Y.T. (2018) Innovation Ecosystem Analysis 1986-2017: A Citation-Based Literature Survey. American Journal of Industrial and Business Management, 8, 2231-2255.

https://doi.org/10.4236/ajibm.2018.811149

Received: October 24, 2018

Accepted: November 25, 2018

Published: November 28, 2018

Copyright ( 92018 by authors and Scientific Research Publishing Inc. This work is licensed under the Creative Commons Attribution International License (CC BY 4.0).

http://creativecommons.org/licenses/by/4.0/

(c) (i) Open Access

\begin{abstract}
This paper uses the method of main path and content analysis to analyze the important scholars, influential journals and key literatures in the field of innovation ecosystem. The theoretical development skeleton of innovation ecosystem research has been clearly constructed. The study shows that the innovation ecosystem theory, as a new field of research, is developing rapidly. The research focuses on three new fields: business, technology and service innovation ecosystem. The research early focused on strategic management and innovation systems, but it focuses on the ecology of various disciplines now. Value co-creation gradually becomes the main driving force to promote the development of innovation ecosystem. Further, based on the structural analysis of documents, the paper constructs a panoramic theoretical framework for the development of the innovation ecosystem from the perspectives of innovation, driving factors, innovation subject, innovation structure, innovation community and innovation risk, putting forward the future research direction of the innovation ecosystem.
\end{abstract}

\section{Keywords}

Innovation Ecosystem, Citation Network Analysis, Main Path Method, Social Network Analysis

\section{Introduction}

With the increasingly fierce global competition, more and more enterprises realize that they can enhance their core competitiveness and create business value through a healthy ecosystem. American scholar Moore first puts forward the new concept of "business ecosystem" in 1993. The emergence of business ecosystem provides a new perspective for enterprises and creates a unique business 
operation model (Adner, 2006; Singer, 2006; Horn, 2005). In the business ecosystem, successful companies can create a "platform" (service, tool, or technology domain, etc.) that allows technology to flow throughout the ecosystem, allowing other ecosystem members to use the platform to achieve their business goals (Moore, 1993; Iansiti and Levien, 2004). Subsequently, the concept of technology ecosystem was proposed and used to describe the relationship between technology and organization. Rosenkopf and Tushman use the system view to analyze inter-organizational relationships and study the co-evolution of technology and organization. In addition, some researchers argue that technology cannot be analyzed in isolation. Dosi's paradigm, Nelson's \& Winter's technological systems and Sood's \& Tellis' platform innovations all emphasize evolutionary analysis of technology as a system. Finally, with the concept of service ecosystem emerges, which is defined as "Create interconnected, relatively independent and self-regulated resource integration systems (Vargo \& Akaka, 2012) by sharing institutional logic and common values exchanged through services", which emphasize that in order to survive, enterprises need to change themselves and resolve conflicts among different roles in the management service ecosystem. To manage these conflicts, Lusch and Nambisan (2015) point out that service ecosystem needs to develop and maintain a "shared worldview" among participants and implement a "participatory architecture" or a service platform to coordinate. At the same time, some researchers have noted that there may be tensions among participants in the service ecosystem due to lack of coordinated guidance to their institutions (Solomon, Surprenant, Czepiel \& Gutman, 1985; Venkatesh, Penaloza \& Firat, 2006; Vargo \& Lusch, 2011).

Nevertheless, there are still many deficiencies and gaps in the study of innovation ecosystem. First of all, the research on innovation ecosystem is still focus on case studies, and theoretical research is at the stage of exploration. Secondly, based on the different perspectives chosen by different authors, the research of innovation ecosystem is dispersed, and it is weakly related to the theory, which weakens the possibility of communication between literature and theory. This paper combs the development path of innovation ecosystem knowledge through the main path method and extends the theoretical framework of the knowledge based on existing theories. Finally this paper builds a framework for the development of innovative ecosystem.

The main contributions of this study are three aspects. First, we present 3 innovation ecosystem development scenarios from previous studies. Second, we demonstrate a novel way of analyzing an academic discipline through citation data. The proposed multiple path method complements and increases the value of the traditional main path methodology. Finally, this paper analyzes the innovation ecosystem through six aspects, and constructs a complete theoretical system block diagram. Through the development of the main path of innovation ecosystem and the combing of the theoretical framework, it can provide new ideas for enterprises to achieve value creation in the future. 


\section{Literature Review and Structure}

To explore the development and evolution of a field, Bibliometrics is a very basic and effective research method. It involves general statistical analysis of relevant research, such as the overall development trend of the field, national distribution, journal distribution and High-yielding scholars. In addition, Bibliometrics is also widely used in scientific research evaluation. This quantitative analysis is objective and clear [1]. It overcomes the shortage of subjectivity in expert evaluation and lays a foundation for basic metrology and research in emerging disciplines. Understanding the development trend of emerging fields is a topic of great concern for science and technology policy-makers [2]. It helps to optimize the allocation of scientific and technological resources and carry out reasonable technology forecasting. Based on this, an attractive direction is to explore the evolutionary footprints and hot topics in emerging areas, so as to reveal the theoretical knowledge base and theme development law of the research. In a certain period of time, the most active development direction of research topic representation has attracted more scientific attention. Knowledge base is the knowledge clustering formed by the co-citation relationship derived from the research topic [3]. At present, many research methods are used to analyze the theoretical knowledge base and research topics, such as historical mapping, co-citation of literature, co-word Analysis and journal atlas. Generally speaking, scholars at home and abroad generally pay attention to the key driving force of innovation on economic and social development, science and technology and economy. The innovation ecosystem has also become a research focus in the field of innovation. Based on the basic ideas of ecology and organic mode, this paper explores the structure, rules, governance and strategy of innovative ecosystem by more efficiency approach, and obtains some research results. Of course, the research on the innovation ecosystem is still in its infancy, and the literature is hard to say. In addition, according to the articles in the main path, it can be seen that the main articles focus on using case or empirical methods to study a specific problem. There are few literatures to sort out the context of this research field. This paper fills the gap and combs the overall framework and theoretical basis for the development of innovative ecosystems. The following (Figure 1) is the overall framework of this article.

\section{Methodologies}

This study applies two citation-based methodologies: the main path method and the measurement of different indexes to reveal the law of its development [4]. The main path method helps comprehend the innovation ecosystem to a more detailed level, while the TLCS, TGCS and h-index are used to rank the influence of innovation ecosystem authors and journals. We also use the growth curve analysis to better grasp the innovation ecosystem development trend. The following sections briefly introduce these methodologies. 


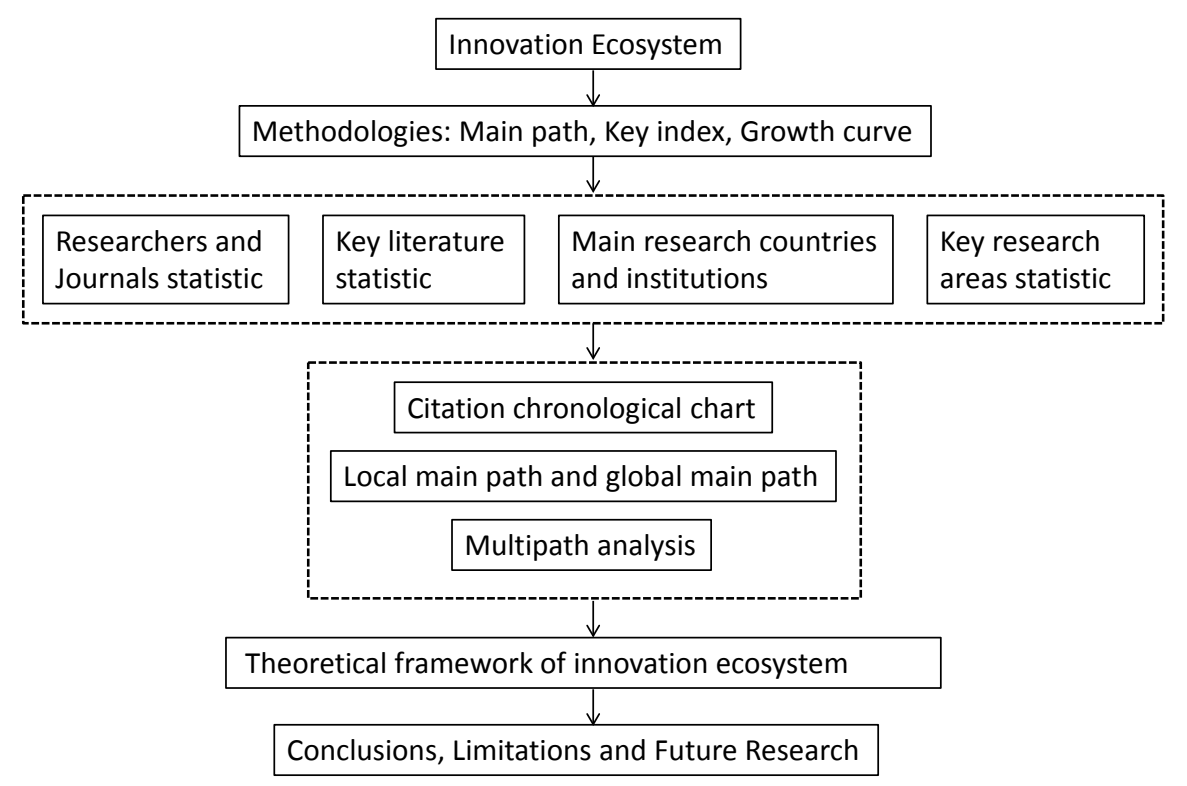

Figure 1. The framework of this paper.

\subsection{Main Path Analysis}

In the course of scientific fields' development, several ideas and opinions are proposed continuously. Along the way, some ideas stay and some fade away. Those opinions that stay usually raise wide and long-lasting attention. This study can find ideas that are proposed in the course of innovation ecosystem development stay and make a significant influence upon this field.

The main path method is different from the traditional literature coupling and co-citation methods. The main path method is more concerned with the connections among nodes in the citation network. Hummon and Doreian (1989) [5] first introduced main path method and use citation information in academic literature or patents to trace the main idea flow in a scientific discipline. When a publication cites a previous work, relevant knowledge will flow from the previous work to the citing publication. This method is based on the citation network and the scientific publications are seen as nodes of a network. Moreover citation information is used to establish links among nodes. It is difficult to trace the flow of ideas if the network grows larger. Hummon and Doreian (1989) suggest an approach to simplify the task in a large citation network: tracing only the "main path". Identifying the importance of each citation link in the network is the first step in finding the main path. The importance of each citation can be measured by counting the times a citation link has been traversed were one exhausts the search from a set of starting nodes to another set of ending nodes. There are several variations of ways to do the count, for example Node pair projection count (NPPC), search path link count (SPLC), search path nodes pair (SPNP), and search path count (SPC). This paper choose to use SPC as it is recommended by Batagelj (2003) [6] as the first choice. In a citation network, a "source" is a node that is cited, but cites no other nodes; a "sink" is a node that cites other nodes, but is not cited. In other words, sources are the origins of 
knowledge, while sinks are the end points of the knowledge dissemination. In this paper, the main path method is used to analyze the key academic papers and the main development of the discipline trend. The local main path algorithm focuses on the maximum SPC value of the current connection, which emphasizes the importance of the local knowledge [7]. Compared with the local main path, the global main path is more concerned with the overall importance of knowledge dissemination. In fact, the two methods are complementary to each other, and it is more convincing to take into account both than to consider only one. Moreover the multiple global main paths is the expansion of the main path, and the application of these three methods will be more systematic, comprehensive and detailed to show the process of the development of innovation ecosystem.

\subsection{Key Index Selection}

In this paper, TLCS (total local citation score), TGCS (total global citation) and $\mathrm{h}$-index were used to measure the innovation ecosystem. The higher the citation frequency, the more important the author is in this field. And then the Authorities and Hubs indicators can provide a new perspective which is determine the vertex importance by adjacent points. Authorities are important recipients of the literature and Hubs are important senders which connected with important $\mathrm{Au}$ thorities. The academic paper could become an important node in the innovation ecosystem literature, if the node is an important recipient and dissemination point of the literature [8].

\subsection{Growth Curve Analysis}

In this paper, the growth curve method is commonly used to project the lifecycle of a physical or social system. Moreover, the future development trend of knowledge is revealed through the analysis of the growth curve of the published literatures in the field of innovation ecosystem. Growth curve analysis is based on the assumption that the growth of objects in a system such as human population growth on earth, bacteria expansion in laboratories. In this approach, when a system develops to a certain degree, resource scarcity and environmental factors will inhibit further growth. It is generally believed that the growth of scientific articles is not at the same rate. It increases a little slow in the beginning. At a certain point, it speeds up exponentially. After passing the "midpoint" (where the growth rate inflects), the growth slows down and eventually reaches a growth limit point. The growth curve has a good match between the logical function and the time series data, so that scholars are able to predict the growth limit, the midpoint, and the life cycle of an S-shaped curve [9].

Mathematically, an S-shaped curve can be represented with a logistic function:

$$
S(t)=\frac{k}{1+\exp \left[-(\ln (81) / t)\left(t-t_{m}\right)\right]}
$$

where $k$ is the growth limit; $t_{m}$ is the midpoint of the growth trajectory; and $\Delta t$, 
the lifecycle, is defined as the time the development takes to grow from $10 \%$ to $90 \%$ of the growth limit.

\section{Data Source and Basic Statistics}

\subsection{Data Source}

The data source of this paper is web of science database, which is the most authoritative and important citation information database in the world. Around the theme of innovation ecosystem research, according to the search strategy of "theme $=$ innovation ecosystem", "type of literature $=$ Article" "the time span $=$ all year", "database $=$ SCI-EXPANDED, SSCI, A\&HCI, CPCI-S, CPCI-SSH, CCR-EXPANDED, IC", for data retrieval of relevant literature retrieval. We obtained a total of 1655 articles. In order to explore the present and future trends of the innovation ecosystem, this paper makes a statistical analysis of the literature published in the field of innovation ecosystem. On the whole, the number of publications on the theme of innovation ecosystem presents a gradual upward trend, as shown in Figure 2. Among them, there is a slow rise period in 1993-2006 years, and the average annual number of posts is not more than 50 . Since 2006, the number of publications has been increasing, reaching 396 in 2016 (due to the incompleteness of the data in 2017). At the same time, from the TLCS (total local citation score) and TGCS (total global citation score), the impact of the literature reflected by the analysis of the relevant literature in the field of influence (TLCS) showed a gradual upward trend. From the overall statistics, the number of papers has been rising steadily. TLCS has been improving steadily and TLGS has been increasing continuously. It shows that more and more scholars pay attention to the research of innovation ecosystem, and the influence of different fields and disciplines is more extensive.

Based on the statistical data of the number of paper published over the years in innovation ecosystem, this paper make full use of the logistic growth curve to predict the trend of papers in the field of innovation ecosystem. From Figure 3, we can obtain that innovation ecosystem experiences an initial stage and now in the process of continuous development period. The logistic growth curve of the trend suggest that innovation ecosystem would enter a rapid development period after 2015 and then the number of published will be saturated and stable in a certain range.

\subsection{Basic Statistic}

\subsubsection{Researchers and Journals Statistic}

Firstly, this paper analyzes the overall situation of the innovation ecosystem. In the field of innovation ecosystem, a total of 6035 authors produced 2030 articles to the deadline. These authors are mainly concentrated in the United States, Britain, China, Canada, Europe and other countries. Many researchers have contributed to the innovation ecosystem field during its development. We apply the TLCS, the TGCS and the h-index to recognize researchers' contribution and 


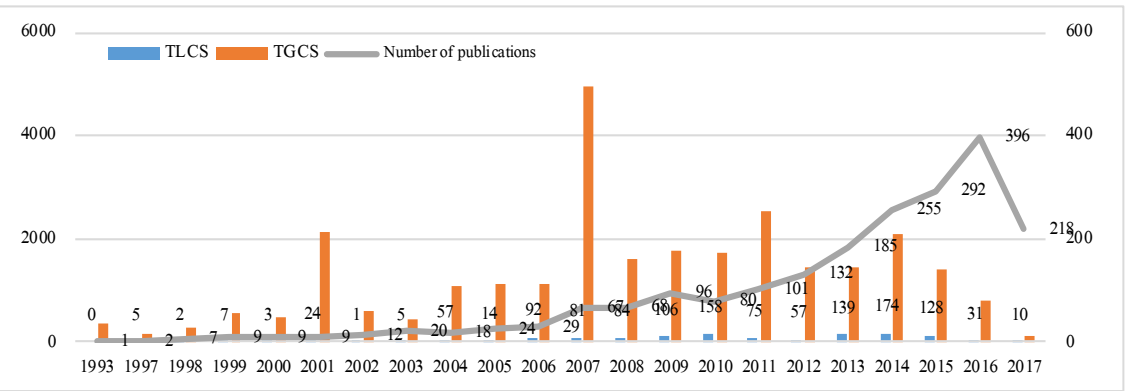

Figure 2. Published papers per year of innovation ecosystem. Data sources: web of science database.

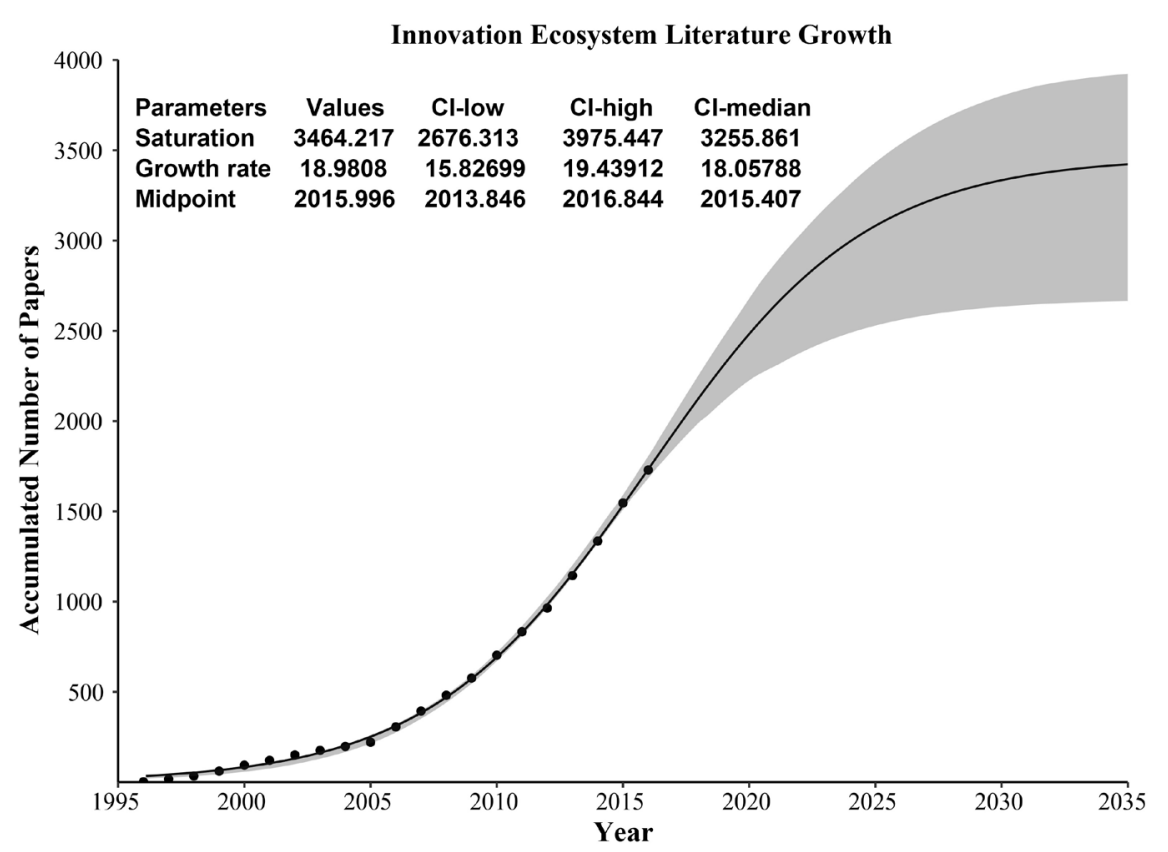

Figure 3. Growth trend of innovation ecosystem. Data sources: web of science database.

influence. Table 1 lists the top 15 authors in the field of innovation ecosystem according to their TLCS. The TGCS ranking and h-index ranking of these authors is also presented. As we can be seen from Table 1, Adner R, Kapoor R, Gawer A, Iansiti Marco and Levien Roy are the top 5 researchers by ranking TLCS. Teece DJ, Adner R, Kapoor R, Iansiti Marco and Levien Roy are the top 5 authors on the basis of TGCS ranking (as shown in Table 1) and the result illustrates the importance of the above authors in the field of innovation ecosystem. At the same time, this paper uses the $\mathrm{h}$-index which means that an author has $\mathrm{h}$ articles, each cited at least $h$ times, while the other articles are cited less than $h$ times each. h-index can take into account the quality and quantity of the individual scientific output to measure so that the evaluation of the influence is more reasonable [10]. Teece DJ, Tiwana A, Vargo SL, Bush AA, Konsynski have higher h-index value in the field of innovation ecosystem. It shows that the scholars have published more quality academic papers in the development of innovative ecosystem, and they have higher academic influence. 
Table 1. Top 15 researchers of innovation ecosystem.

\begin{tabular}{ccccc}
\hline Authors & TLCS & TGCS & H index & Frequency $^{\mathrm{a}}$ \\
\hline Adner R & 194 & 529 & 13 & $24 / 1375 / 1345 / 1174 / 1161 / 57.29$ \\
Kapoor R & 109 & 289 & 6 & $20 / 380 / 370 / 339 / 332 / 19$ \\
Gawer A & 69 & 212 & 7 & $9 / 374 / 365 / 303 / 298 / 41.56$ \\
Iansiti Marco & 53 & 239 & 4 & $8 / 322 / 322 / 314 / 314 / 40.25$ \\
Levien Roy & 53 & 239 & 1 & $1 / 243 / 243 / 243 / 243 / 243$ \\
Cusumano MA & 52 & 164 & 18 & $55 / 975 / 965 / 882 / 875 / 17.73$ \\
Nambisan S & 51 & 179 & 21 & $72 / 1454 / 1422 / 1280 / 1260 / 20.19$ \\
Basole RC & 44 & 143 & 8 & $38 / 367 / 301 / 301 / 281 / 9.66$ \\
Teece DJ & 39 & 1869 & 25 & $49 / 6891 / 6782 / 6009 / 5977 / 140.63$ \\
Bush AA & 33 & 122 & 20 & $283 / 1986 / 1802 / 1659 / 1582 / 7.02$ \\
Konsynski B & 33 & 122 & 20 & $96 / 2186 / 2155 / 1921 / 1909 / 22.77$ \\
Tiwana A & 33 & 122 & 25 & $81 / 2093 / 2005 / 1748 / 1710 / 25.84$ \\
Vargo SL & 33 & 203 & 23 & $53 / 5323 / 5155 / 2918 / 2880 / 100.43$ \\
Akaka MA & 30 & 69 & 6 & $6 / 168 / 164 / 121 / 119 / 28$ \\
Ceccagnoli M & 28 & 65 & 8 & $15 / 433 / 420 / 383 / 374 / 28.87$ \\
\hline
\end{tabular}

${ }^{\mathrm{a}}$ Frequency $=$ Total Publications/Sum of Times Cited/Without self citations/Citing articles/Without self citations/Average citations per item. Data sources: Using Pajek tools to sort out data.

At the same time, these articles are distributed in 1031 journals, mainly involving 20 areas, such like economics, management, information science and ecology and so on. It shows that the field of innovation ecosystem is more multidisciplinary. We apply again the TLCS index, TGCS index and h-index to identify the influential journals published in the field of innovation ecosystem (as shown in Table 2). Havard Business Review ,Strategic Management Journal, Mis Quarterly, Research Policy, Journal of Information Technology are the top 5 journals according to the rank of TLCS. These journals are important journals in the field of innovation ecosystem.

\subsubsection{Key Literature Statistic}

In this paper, the key literature in the field of innovation ecosystem is identified by means of set point (Authorities) and dissemination point (Hubs).Authorities refer to the articles that cited by a lot of articles, and that means it is important to spread the knowledge [11]. On the contrary, the article which citing a lot of articles is the Hubs, and that is an important node to receive knowledge [12]. From Table 3, higher Authorities are: Adner R2010, Adner R2006, Tiwana A2010, Makinen SJ2013, Ceccagnoli M2012. It shows that the above articles are important in the diffusion of knowledge in this field. Higher Hubs literature are: West J2013, Makinen SJ2013, Makinen SJ2014, Dedehayir O2011, Nambisan S2013, indicating that these articles are important recipients in the process of knowledge dissemination in the field. Moreover, comparing to the indexes of 
Table 2. Top 15 most influential journals of innovation ecosystem.

\begin{tabular}{|c|c|c|c|}
\hline Journals & TLCS & TGCS & $\mathrm{H}$-index \\
\hline HARVARD BUSINESS REVIEW & 151 & 853 & 11 \\
\hline STRATEGIC MANAGEMENT JOURNAL & 143 & 4025 & 8 \\
\hline MIS QUARTERLY & 68 & 312 & 9 \\
\hline RESEARCH POLICY & 50 & 238 & 8 \\
\hline JOURNAL OF INFORMATION TECHNOLOGY & 40 & 117 & 6 \\
\hline $\begin{array}{l}\text { COLLABORATION AND COMPETITION IN BUSINESS } \\
\text { ECOSYSTEMS }\end{array}$ & 39 & 55 & 6 \\
\hline $\begin{array}{c}\text { INTERNATIONAL JOURNAL OF TECHNOLOGY } \\
\text { MANAGEMENT }\end{array}$ & 36 & 238 & 8 \\
\hline $\begin{array}{l}\text { JOURNAL OF PRODUCT INNOVATION } \\
\text { MANAGEMENT }\end{array}$ & 36 & 109 & 4 \\
\hline INFORMATION SYSTEMS RESEARCH & 35 & 137 & 3 \\
\hline TECHNOVATION & 35 & 124 & 6 \\
\hline CALIFORNIA MANAGEMENT REVIEW & 32 & 280 & 5 \\
\hline MIT SLOAN MANAGEMENT REVIEW & 28 & 96 & 3 \\
\hline $\begin{array}{l}\text { PROCEEDINGS OF THE NATIONAL ACADEMY OF } \\
\text { SCIENCES OF THE UNITED STATES OF AMERICA }\end{array}$ & 28 & 1253 & 9 \\
\hline ECOSYSTEMS & 25 & 1955 & 19 \\
\hline R \& D MANAGEMENT & 24 & 166 & 5 \\
\hline
\end{tabular}

Data sources: Using Pajek tools to sort out data.

Hubs and Authorities, Li YR, 2009 The technological roadmap of Cisco's business ecosystem; Basole RC, 2009 Visualization of interfirm relations in a converging mobile ecosystem, Adner R, 2010 Value creation in innovation ecosystems. how the structure of technological interdependence affects firm performance in new technology generations, Dedehayir O, 2011 Measuring industry clockspeed in the systemic industry contex, West J, 2013 Evolving An Open Ecosystem: the Risk and Fall of the Synbian Platform, Makinen SJ, 2013 Business Ecosystems' Evolution-An Ecosystem Clockspeed Perspective etc., have high values of both Authorities and Hubs' values, which shows that these papers are actually vital nodes in the field of innovation ecosystem.

\subsubsection{Main Research Countries and Institutions}

Further, this paper makes a statistical analysis of the major countries and research institutes in the field of innovative ecosystems, revealing the relationship between the development of innovative ecosystems and the existence of countries. As the economic downturn in Japan and the rebounded in the United States after the 1990s, the sustained development of Silicon Valley (world innovation center) has a great impact on the traditional innovation model. The introduction of the concept of business ecosystem enlightens researchers and policy makers of national innovation. In 2004, the United States released a series of research reports entitled "Consolidating the National Innovation Ecosystem. It 
Table 3. Most influential papers according to Authorities and Hubs.

\begin{tabular}{|c|c|c|c|}
\hline Authories & Papers & Hubs & Papers \\
\hline 0.056732 & $\begin{array}{l}\text { West J, 2013, ADV STRATEG } \\
\text { MANAGE, V30, P27 }\end{array}$ & 0.652523 & $\begin{array}{l}\text { West J, 2013, ADV STRATEG } \\
\text { MANAGE, V30, P27 }\end{array}$ \\
\hline 0.090003 & $\begin{array}{l}\text { Li YR, 2009, TECHNOVATION, } \\
\text { V29, P379 }\end{array}$ & 0.106831 & $\begin{array}{c}\text { Li YR, 2009, TECHNOVATION, } \\
\text { V29, P379 }\end{array}$ \\
\hline 0.094283 & $\begin{array}{l}\text { Basole RC, 2009, J INF } \\
\text { TECHNOL, V24, P144 }\end{array}$ & 0.106831 & $\begin{array}{l}\text { Basole RC, 2009, J INF } \\
\text { TECHNOL, V24, P144 }\end{array}$ \\
\hline 0.704588 & $\begin{array}{l}\text { Adner R, 2010, STRATEGIC } \\
\text { MANAGE J, V31, P306 }\end{array}$ & 0.106831 & $\begin{array}{c}\text { Adner R, 2010, STRATEGIC } \\
\text { MANAGE J, V31, P306 }\end{array}$ \\
\hline 0.065454 & $\begin{array}{c}\text { Dedehayir O, 2011, } \\
\text { TECHNOVATION, V31, P627 }\end{array}$ & 0.292808 & $\begin{array}{c}\text { Dedehayir O, 2011, } \\
\text { TECHNOVATION, V31, P627 }\end{array}$ \\
\hline 0.121507 & $\begin{array}{c}\text { Makinen SJ, 2013, ADV STRATEG } \\
\text { MANAGE, V30, P99 }\end{array}$ & 0.351501 & $\begin{array}{c}\text { Makinen SJ, 2013, ADV } \\
\text { STRATEG MANAGE, V30, P99 }\end{array}$ \\
\hline 0.12048 & $\begin{array}{c}\text { Ceccagnoli M, 2012, MIS QUART, } \\
\text { V36, P263 }\end{array}$ & 0.152331 & $\begin{array}{c}\text { Kapoor R, 2013, ADV } \\
\text { STRATEG MANAGE, V30, P3 }\end{array}$ \\
\hline 0.294151 & $\begin{array}{c}\text { Tiwana A, 2010, INFORM SYST } \\
\text { RES, V21, P675 }\end{array}$ & 0.131203 & $\begin{array}{c}\text { Zahra SA, 2012, BUS HORIZONS, } \\
\text { V55, P219 }\end{array}$ \\
\hline 0.040337 & $\begin{array}{c}\text { Ghazawneh A, 2013, INFORM } \\
\text { SYST J, V23, P173 }\end{array}$ & 0.260469 & $\begin{array}{l}\text { Nambisan S, 2013, ENTREP } \\
\text { THEORY PRACT, V37, P1071 }\end{array}$ \\
\hline 0.028818 & $\begin{array}{l}\text { Chesbrough HW, 2007, CALIF } \\
\text { MANAGE REV, V50, P57 }\end{array}$ & 0.131899 & $\begin{array}{l}\text { Selander L, 2013, J INF } \\
\text { TECHNOL, V28, P183 }\end{array}$ \\
\hline 0.573709 & $\begin{array}{c}\text { Adner R, 2006, HARVARD BUS } \\
\text { REV, V84, P98 }\end{array}$ & 0.131837 & $\begin{array}{l}\text { Thomas LDW, 2014, ACAD } \\
\text { MANAGE PERSPECT, V28, P198 }\end{array}$ \\
\hline 0.065454 & $\begin{array}{l}\text { Teece DJ, 2007, STRATEG } \\
\text { MANAGE J, V28, P1319 }\end{array}$ & 0.14388 & $\begin{array}{c}\text { Gawer A, 2014, J PROD } \\
\text { INNOVAT MANAG, V31, P417 }\end{array}$ \\
\hline 0.06808 & $\begin{array}{l}\text { Gawer A, 2008, MIT SLOAN } \\
\text { MANAGE REV, V49, P28 }\end{array}$ & 0.308062 & $\begin{array}{l}\text { Makinen SJ, 2014, J PROD } \\
\text { INNOVAT MANAG, V31, P451 }\end{array}$ \\
\hline 0.081914 & $\begin{array}{c}\text { Iyer B, 2008, HARVARD BUS REV, } \\
\text { V86, P58 }\end{array}$ & 0.110669 & $\begin{array}{c}\text { Clarysse B, 2014, RES POLICY, } \\
\text { V43, P1164 }\end{array}$ \\
\hline 0.121507 & $\begin{array}{c}\text { Garnsey E, 2008, IND INNOV, } \\
\text { V15, P669 }\end{array}$ & 0.185977 & $\begin{array}{c}\text { Gawer A, 2014, RES POLICY, } \\
\text { V43, P1239 }\end{array}$ \\
\hline
\end{tabular}

Data sources: Using Pajek tools to sort out data.

states that the future leadership of technology and innovation in the United States will be based on a new system model, the Innovation Ecosystem (PCAST, 2004).

According to the statistics in Figure 4, the top three are the United States (579), the United Kingdom (246), and China (201). In 2012-2013, the American Academy of Sciences published "Rising Challenges: America's Innovative Policies for the Global Economy" and "Best Practices for National and Regional Innovation Systems: Competition in the 21st Century". So the United States is far ahead of other countries in terms of the total amount and quality of innovation ecosystem papers. In 2013, the European Union officially released Open Innovation 2.0, saying that Open Innovation 2.0 will become the "new official language" [13]. It mentions that in the third phase, EU will focus on the innovation ecosystem perspective through the Horizon 2020 program, and in June 2013, an international forum on the theme of "Open Innovation 2.0" was held in Dublin. 


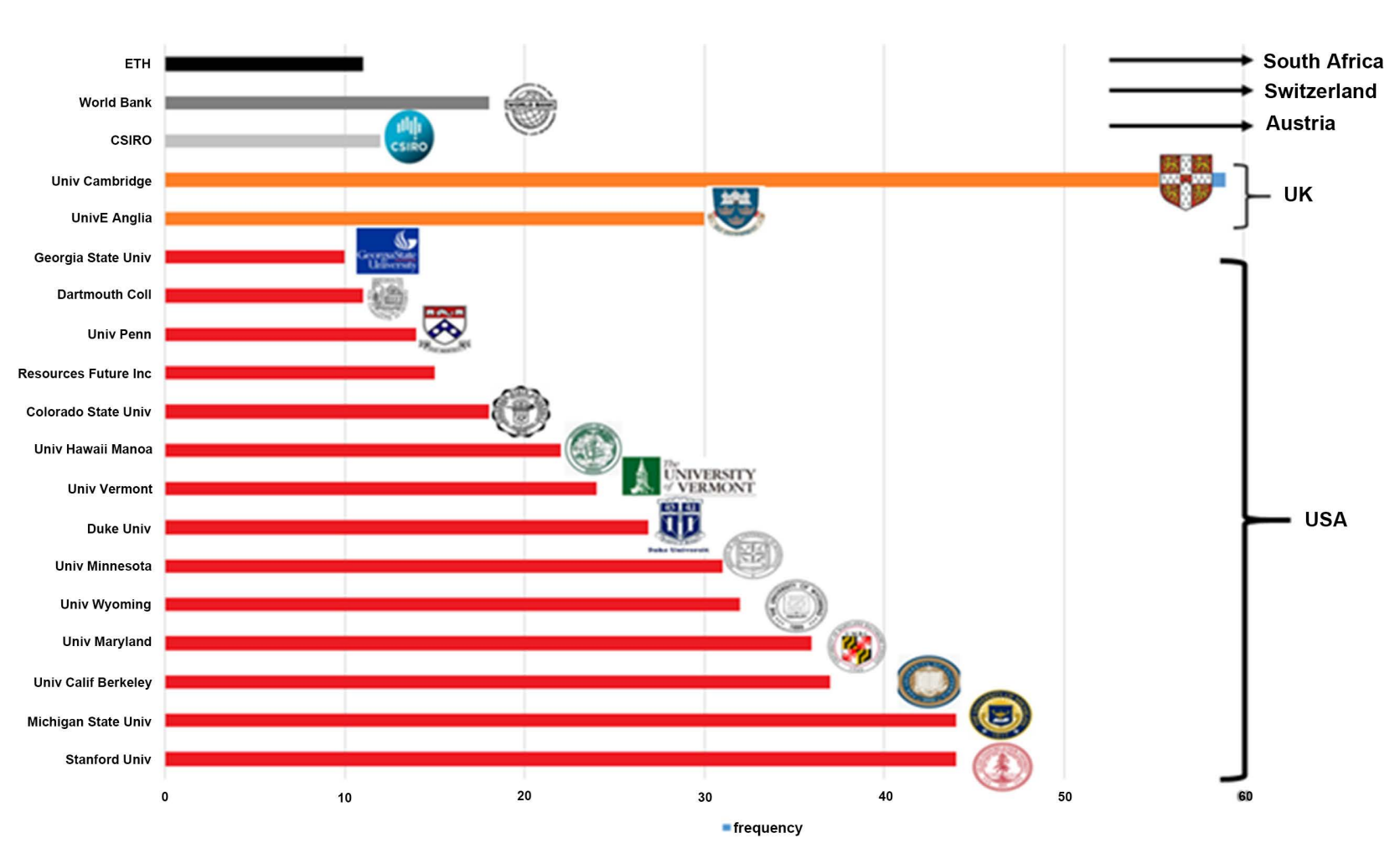

Figure 4. Top 20 research institutes of innovation ecosystem. Data sources: web of science database.

In addition, it is worth noting that there is only one developing country China among the top 10 countries. In China, the economic and social development has entered a "new normal" transition period. The state supports the public's policy initiatives for innovation and entrepreneurship. In recent years, Chinese scholars have paid more attention to the innovation-driven development policy in order to realize the transformation and upgrading of the real economy. The rest are all developed countries, with 841 articles published in European countries (including Britain); besides, the main research institutions are mainly concentrated in the United States (14) and the United Kingdom (2). The University of Cambridge in the United Kingdom ranks first with 59 articles, while the University of Stanford and the University of Michigan in the United States rank second with 44 articles. Therefore, the research on innovation ecosystem has become the most important research area in developed countries.

\subsubsection{Key Research Areas Statistic}

In order to dig out the main development direction of innovation ecosystem, this paper uses co-citation and word clouding technology to do text mining and topic clustering analysis on the literature of innovation ecosystem. As shown in Figure 5, based on co-citation technology high-frequency keywords in the field of innovation ecosystems mainly include innovation ecosystem, business ecosystem, service ecosystem, and the sustainability of technological innovation development.

From the perspective of text mining in this field, various themes can be divided into different levels. As shown in Figure 6, the most popular areas of research 


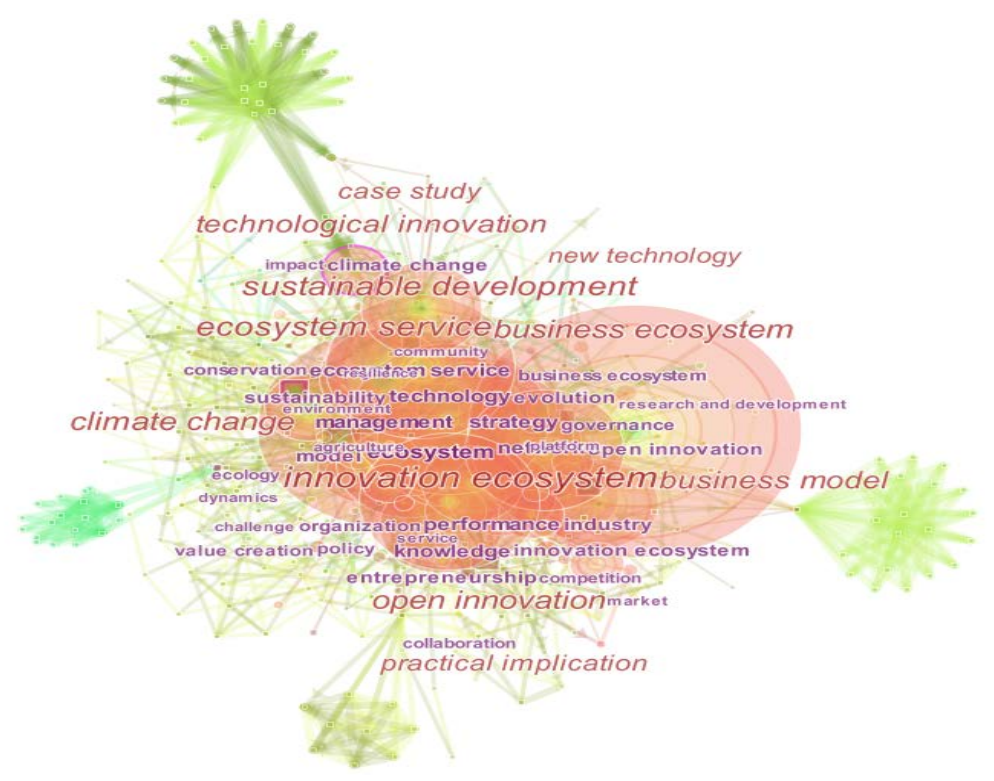

Figure 5. The co-citation clustering. Data sources: Using Citespace tools to sort out data.

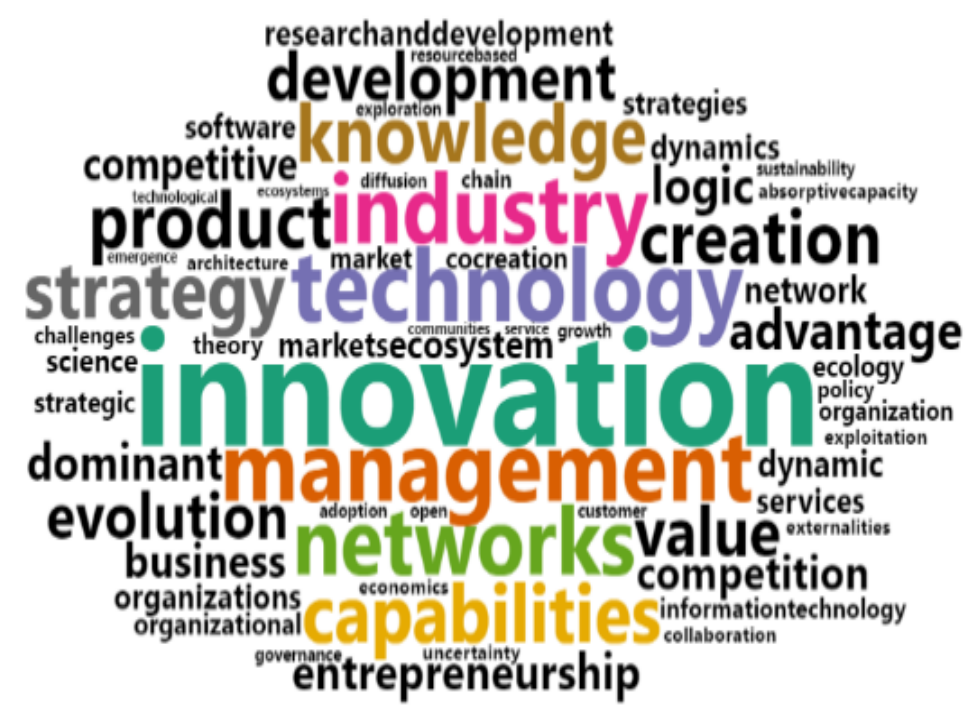

Figure 6. Text-mining clustering. Data sources: Using word cloud tools to sort out data.

are mainly knowledge, industry, technology, innovation, management, network, capabilities and other fields. Secondly, R\&D, product, value creation, system evolution, entrepreneurship and competition are also hot research areas.

\section{Main Paths Analysis}

\subsection{Citation Chronological Chart}

In order to find a clearer developing path of innovation ecosystem, citation relations are found among scientific literature and the key directions in each research phase, Figure 7 shows the citation chronological chart of 30 articles with 


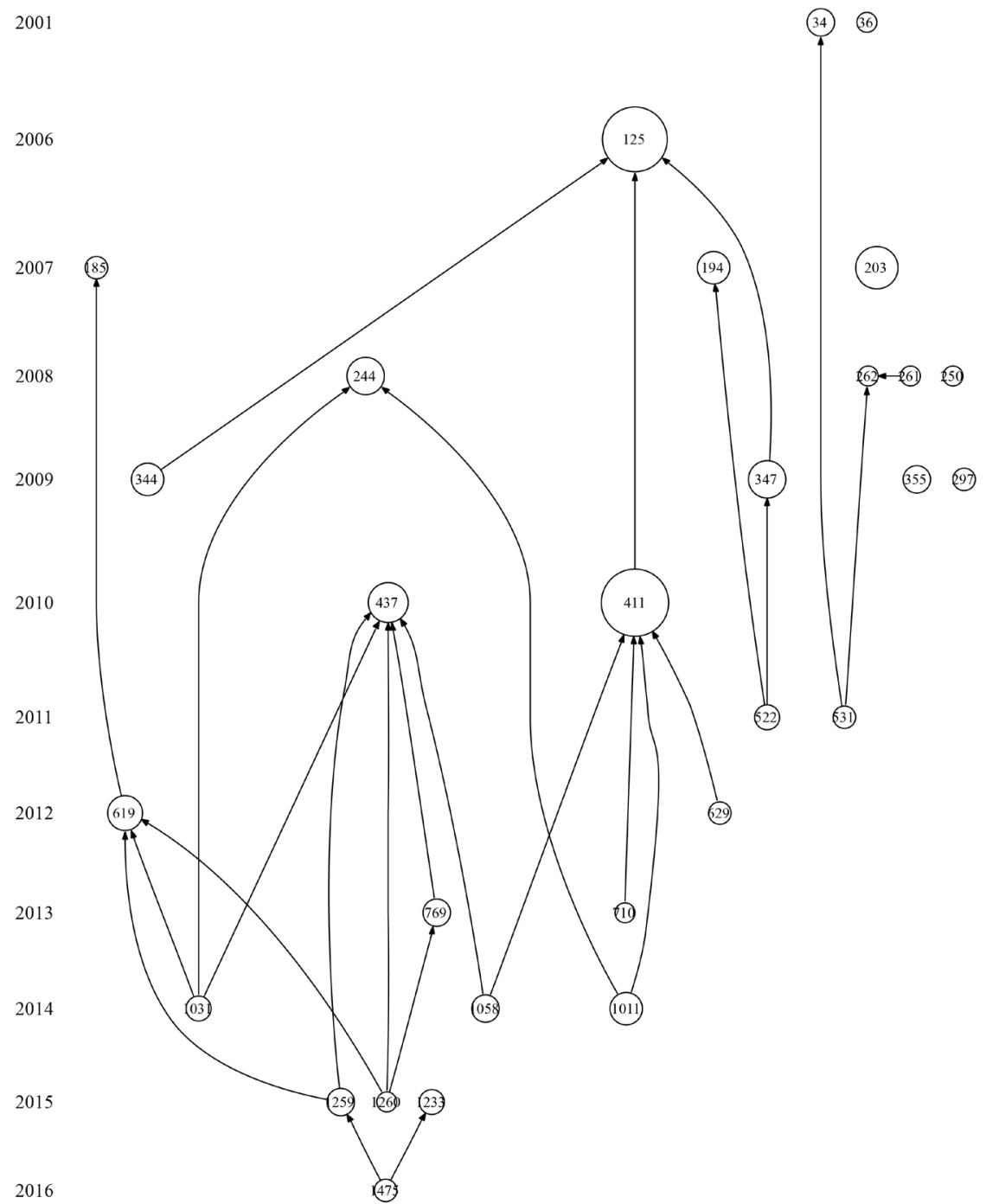

Figure 7. Citation chronological chart of innovation ecosystem. Data sources: Using Histcite $^{\mathrm{TM}}$ tools to sort out data.

the highest cited frequency in the field of innovation ecosystem [14]. The number is limited to 30 articles based on the following considerations: first of all, if the chart involves large number of literature references which mean citing and cited more frequently, may cause the chronological chart more complex or present to be circular citation network, thus weakening the visual effect; Secondly, if the literature involved is limited, we cannot find out the main thread of innovation ecosystem research from the literature [15]. Each circle in Figure 7 represents 1 paper, the size of the circle representing the number of citations to the literature; the line with arrows represents the reference relationship between the nodes of the literature; the arrow points to the cited literature. In Figure 7, the number of nodes is 30 , the number of links is 26 , the maximum number of citations is 70 , the minimum cited frequency is 6 , and there are some scattered 
points and relations. Due to the emerging field of innovation ecosystem itself, it does not form a complete path on the basis of important literature research node in the field of Innovation Ecosystem, and also shows that the innovation ecosystem itself is not mature and is still in the expanding process.

\subsection{Local Main Path and Global Main Path}

Through the combination of local main path and global main path, the whole process of innovation ecosystem development is systematically discovered. Figure 8(a) shows the local main path of innovation ecosystem development, namely, the knowledge dissemination of each connection point is the most important node of literature in the field of innovation ecosystem research. Arrows represent the flow of knowledge. The thickness of the middle line represents the size of the SPC value, and the thicker the line, the more important the path is.

The local main path consists of 18 papers. Adner (2006) recognized that the value of an industry ecosystem as a whole far exceeds the sum of business operations or technical specifications owned by different enterprises individually [16]. Therefore, in order to meet customers' needs, enterprises need to enhance innovation and value level through complementary collaboration with other enterprises in the business innovation ecosystem, such as technology, products, services, and so on. Meanwhile they should consider the integration risks in the system. Subsequently, from the value-driven aspect, Adner (2010) continued his research thinking to study the interdependence of technology in ecosystems and the role of vertical integration in product life cycle. Innovation needs to rely on the external environment changes and the participation of system members [17]. During the last period of the local main path, Adner (2016) discussed the reason behind the speed of technology substitution from the perspective of technology and organizational evolution on the basis of strategic management theory and evolutionary economics theory [18]. Adner use case research to consider the changing process when core technology is embedded in the ecosystem under certain technology level. In 2017, Adner published a structuralist approach to conceptualizing ecosystem construction, providing a clear definition of ecosystem structure, describing the semantics of ecosystem structure and the characteristics of all ecosystem strategy aspects. This approach provides a clear understanding of the relationships among ecosystems and a range of alternative structures such as business models, platforms, competition, multilateral markets, networks, technology systems, supply chains, and value networks [19].

In the context of the business ecosystem development, from a technical point of view, Dedehayir O (2011) measures the length of time that how long an industry has been replaced by other independent secondary industries who can provide similar technology. It is believed that the continuous change of industry is due to the continuous progress of technology, which is the main driving factor of innovation [20]. Subsequently, Kapoor R (2013) expanded the research content of business ecosystem, using the second-hand data of 7525 hospitals from 1995 to 2006 in the AHA database to analyze how the changeable organizational 


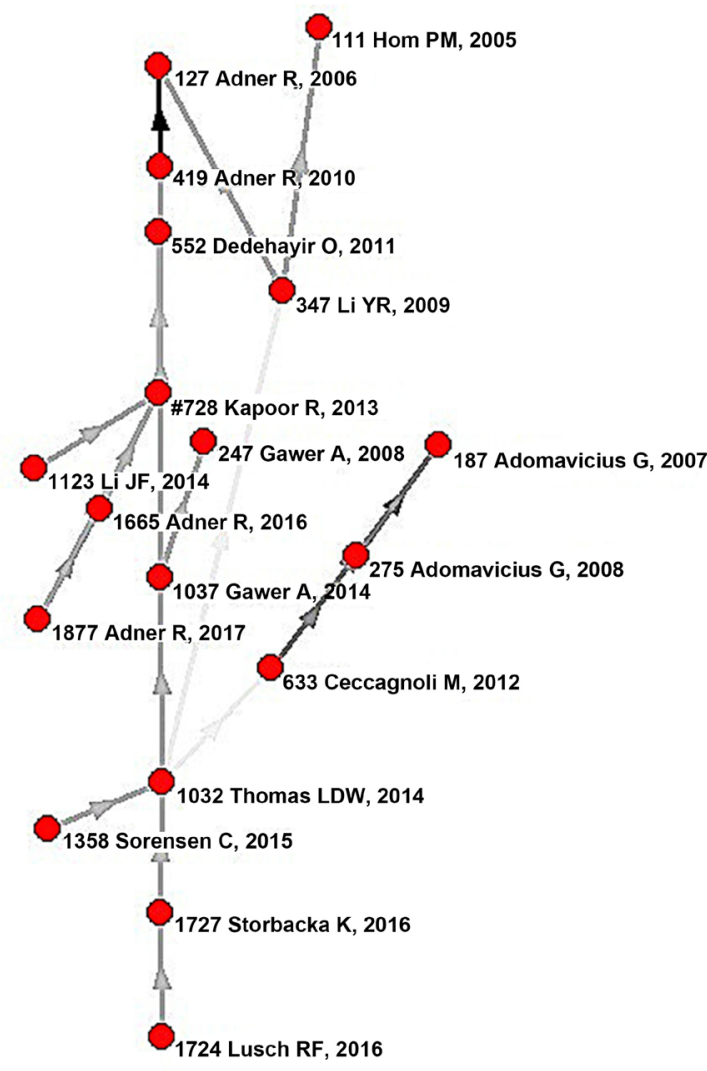

(a)

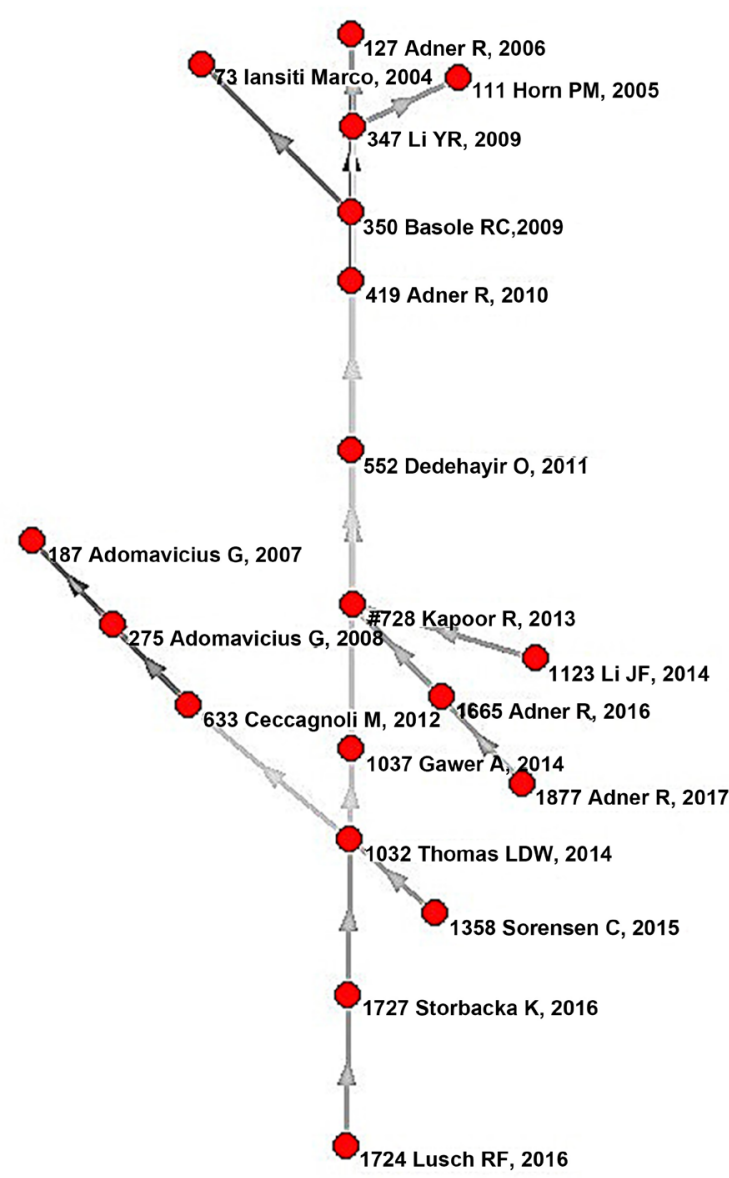

(b)

Figure 8. (a) The local main path; (b) The global main path. Data sources: Using Pajek tools to sort out data.

form in complementary activities affects the investment in new science and technology [21]. On the basis of this study, Li JF (2014) focus on the areas of technology, from a policy-driven perspective, using case studies in China and Britain to illustrate the relationship between biomedical policies and entrepreneurs' R\&D investment strategies in the business ecosystem [22].

Based on Kapoor R's research, Gawer (2014) summarized the recent industry platform literature, divided the platform types into two main categories: internal platform (enterprise-specific platform), external platform and industry platform [23]. In 2008 Gawer explained the significance and methodology of building a platform. The construction of an industry platform includes not only a company's technology or service, but also a complementary ecosystem generated by a variety of businesses [24]. As a result, become a platform leader needs different business and technical strategies, not just a successful independent product. Thomas LDW continued to work on platform concepts in 2014, and the difference from Gawer's research is that Thomas jumps out of business ecosystem concepts to identify 4 main flows. They are: Organizational Ecosystem, Product Family Platform, Market Intermediation Platform and Platform Ecosystem. Each direction has its own characteristics and internal logic which are strongly 
different from other flows. From the perspective of strategic management theory, Horn (2005) focused on vertical integration which emphasize on core technology. The focus of research shifted from production to service. And ultimately the direction of research transfer from the overall thinking of enterprises, encouraging enterprises to integrate internally, and find strategic partners to achieve industrial networking [25]. Li YR (2009) emphasized the symbiotic evolution of business ecosystem on the basis of vertical integration, and emphasized that business managers can use the symbiotic, platform, and co-evolution to meet the challenges of the changeable business environment [26].

Adomavicius (2008) understands technology evolution by emphasizing the relationship between multiple technology dynamics and high interdependence relationships. By establishing a technology ecosystem, they describe the interaction and evolution of the three role: components, products and applications within an ecosystem [27]. Further, Adomavicius's (2008) article in 2008 built an IT ecosystem based on the technology ecosystem, providing a formal point of view for structural analysis of IT trends. And this IT ecosystem can reduce IT complexity for practitioners to make IT investment decisions [27]. Ceccagnoli (2011) discussed whether independent software vendors (ISVs) can improve their business performance by participating the ecosystems in the enterprise software industry and how to use appropriate mechanisms can benefit partners in the system [28]. Ceccagnoli emphasized that platforms are not just technology exchanges but value co-creation. Sorensen $\mathrm{C}$ collated and combed the previous literature through the case of smart phone.

With the further study of Storbacka K (2016), the main body of the study focused on the value creation and how to build a service innovation ecosystem. From the change of micro-foundation of strategic management, the micro-foundation of service innovation ecosystem is the participation of members [29]. From an interdisciplinary perspective, members are seen not only as human beings, but also as a combination of machines and a variety of human and machine. Member participation is considered to be the basis for members' inclined attraction and resource interactions in service ecosystems. Lusch RF (2016) continued to study the ecosystem of service innovation with a brief introduction and comment on this particular issue from the interdisciplinary perspective of service-led logic [30]. It provides insights into economics, ecosystem theory, philosophy, service science, sociology, strategic management and systems science, and shares views and suggestions on resource integration, value creation, institutions and service ecosystems.

Figure 8(b) depicts the global main path. Comparing with the local main path, the global main path develops in the similar way as the local main path. From the global perspective, two articles, Iansiti (2004) and Basole (2010), have been added. Iansiti (2004) elaborates on the innovation ecosystem from the perspective of niche. Iansiti believes that within a business innovation system there are different but interrelated enterprises. Once one niche changes, others will follow [31]. Basole (2010) visualized the mobile innovation ecosystem con- 
sisting of mobile terminals from innovation networks and complex systems. Visually explore the complex relationships among them and the relationships that influence their choice of innovation strategies or business models [32].

Combining the above local and global main path analysis, the local and global main paths are identified by three main elements in Figure 9. The number represents the document position in the complete database, and the arrow represents the process of development and change. The research literature focuses on the main subject of innovation activities, driving factors and the type of innovation ecosystem. First of all, it reflects that the main subject of innovation activities mainly concentrates on the industry level. The key node literature explores the interaction among different enterprises at a certain industry level within the innovation ecosystem. In the evolution and development of the late-stage activity subject, there are also documents related to the national level and the micro-level of the enterprises' internal environment. Secondly, the types of innovative ecosystem have evolved from business-oriented type, which focuses on the relationship among enterprises in the business community to technological type. On the basis of business development, the researchers pay more attention to the development and change of technology in the ecosystem. And finally shift to service-oriented type, from linear thinking to network thinking. More service-oriented intelligence systems are included in the research area. Finally, the evolution process of the driving factors of the whole innovation ecosystem is discussed. As we can see in Figure 9, the elements which drive the continuous development of the innovation ecosystem, from strategy-driven development to key technology-driven development, extended to today's value creation driven. This change reflects the deepening development of innovative ecosystem.

The local main path and global path mentioned above describe the whole development process of the innovation ecosystem. However the local main path and the global path are based on the SPC value, they may omit some important literature and cannot completely comb the literature in different research zones. On the basis of the local main path and the global main path, this paper forms a multi-path of the innovation ecosystem, which can show the theme and development of the innovation ecosystem at different stages.

\subsection{Multipath Analysis}

Based on the analysis of local and global principal paths, the study of innovation ecosystem is divided into two parts. Firstly, under the framework of innovation system research, the regional (industry) and national innovation ecosystem form the middle and macro level of innovation ecosystem. Another way is to analyze the contents of related disciplines from the perspective of ecology. To study the interaction among technology, knowledge process and economic society from the perspective of ecology, for example: knowledge ecology, technology ecology, service ecology and so on. Business ecosystem traces upward, while knowledge, technology and service ecology extend downward. The combination of the two 


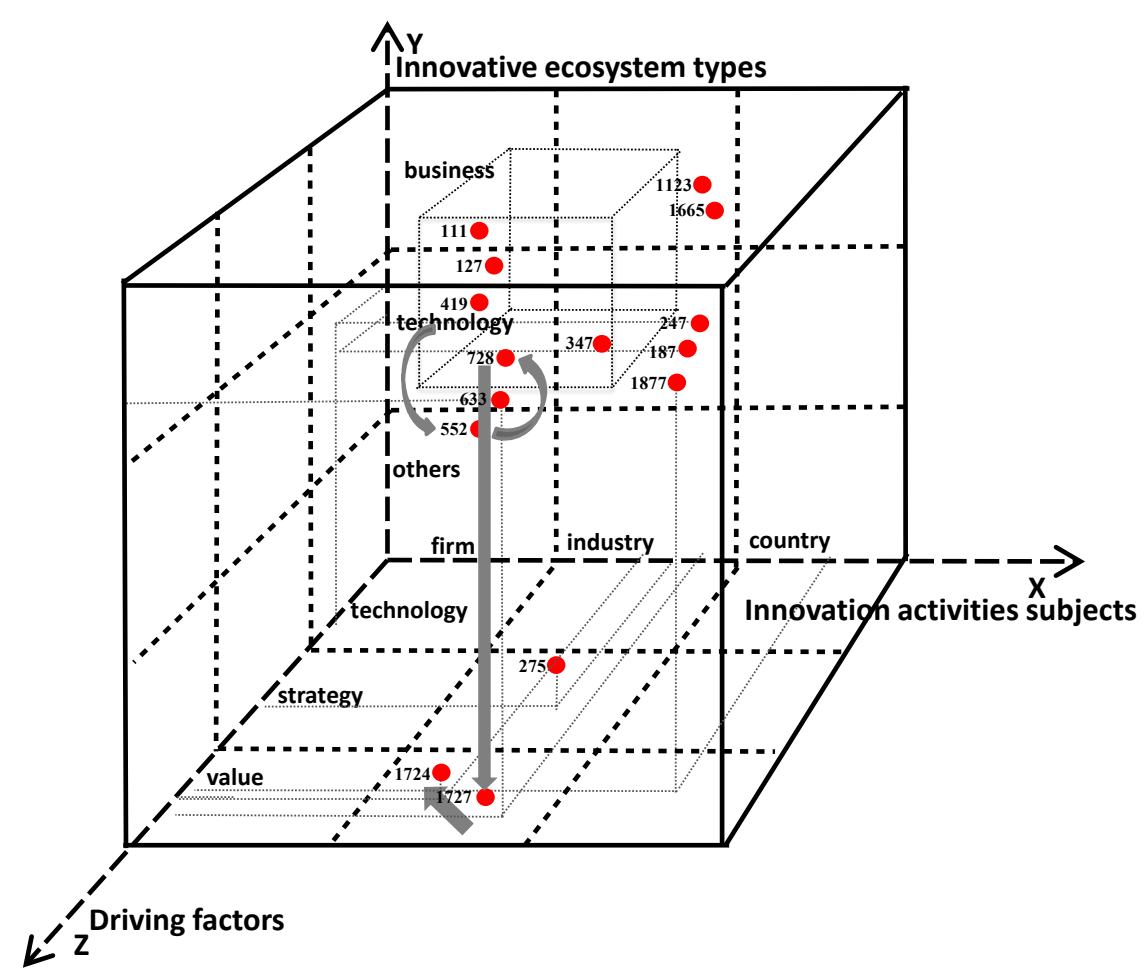

Figure 9. Local and global main path development trend. Data sources: web of science.

sides fully reflects the formation and development of innovation system from the perspective of ecology which is innovation ecosystem. This paper takes the research on the relationship among enterprises in innovation ecosystem as the medium industry level, and the internal interaction among enterprises as the micro enterprise level. Subsequently, this paper further draws a multi-path map to further demonstrate the development stage of the innovation ecosystem. As shown in Figure 10.

From Figure 10, we find that the important development of the innovation ecosystem start from the business ecosystem. At this stage, scholars have focused their attention on the concept and construction of business ecosystems and the exploration of relationships among members of business ecosystems. From Table 4, we can see that the business innovation ecosystem has a steady and increasing trend. According to the centrality, the key words are: business ecosystem, strategy, business model, management, network, development and innovation, network, value creation, etc. After building the basic structure of the business ecosystem, the development of the innovation ecosystem enters the technical field of different industries, forming the technological innovation ecosystem, including the IT ecosystem, payment ecosystem and other development processes in different paths. Finally, develop to the service ecosystem, seen as Table 4. The amount of technical innovation ecosystem is increasing, the key words are mainly concentrated in knowledge, management, technology, R\&D investment, industry and so on. The number of papers published in the service ecosystem also shows a gradual upward trend. The key words mainly focus on 


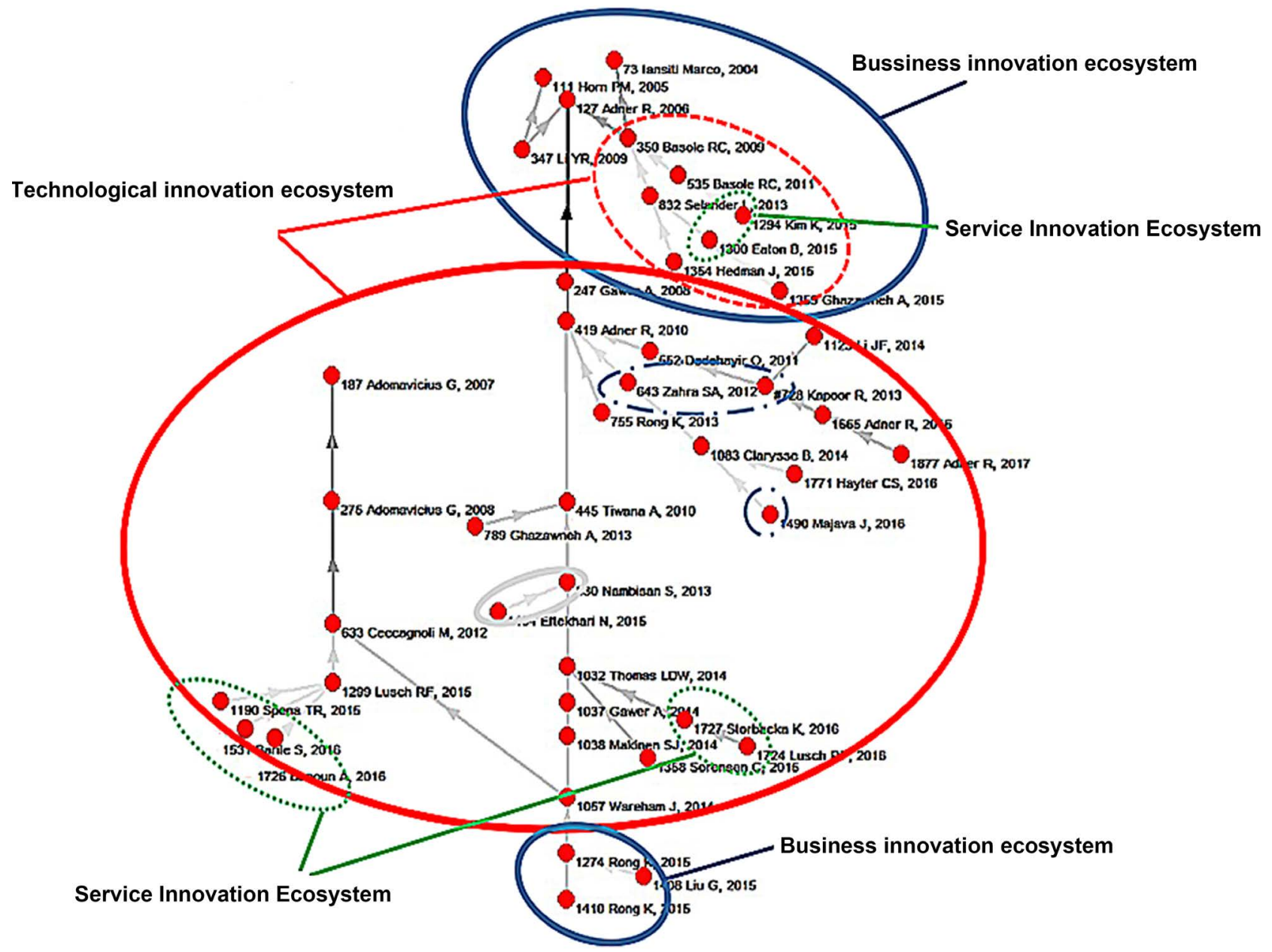

Figure 10. Multiple global main paths of innovative ecosystem. Data sources: Using Pajek tools to sort out data.

sustainability, service ecology, dominant logic, evolution and development. After the technological ecology develops to a certain stage, we have a new understanding of the business ecosystem, and discuss the new development of the business ecosystem under the situation of transnational corporations and the Internet of Things.

\subsection{Theoretical Framework of Innovation Ecosystem}

Through the analysis of local main path, global main path and multipath, this paper describes the research of innovation ecosystem from complex to simple, and finally classifies the development of innovation ecosystem into six basic elements. In this paper, the literature on innovative ecosystem is structured. From the perspective of process theory, this paper combs and integrates the literature in this field, and finally gets the theoretical framework of innovation ecosystem, as shown in Figure 11. According to the development and change of the innovation ecosystem, the theory mainly constructed from six aspects. Firstly, the theoretical perspective of scholars' research mainly includes: the perspective of evolutionary economics based on review articles; the perspective of 
Table 4. Development zones of innovation ecosystem.

\begin{tabular}{|c|c|c|}
\hline Topic (volume) & Development trend & Cluster graph \\
\hline Business innovation ecosystem (513) & 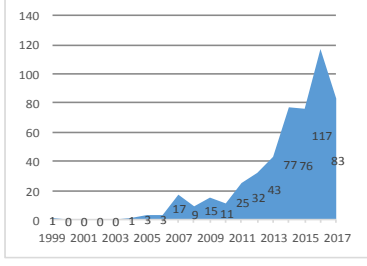 & $\begin{array}{l}\text { model } \\
\text { mystem }\end{array}$ \\
\hline Technological innovation ecosystem (766) & 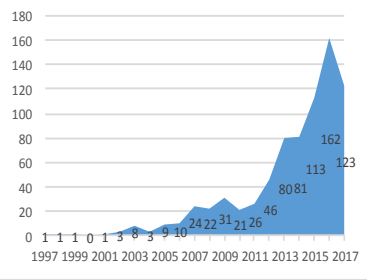 & \\
\hline Service innovation Ecosystem (619) & $\begin{array}{l}140 \\
120 \\
100 \\
80 \\
60 \\
40 \\
20 \\
0 \\
01000001-525-571022221822^{32} \\
19971999200120032005200720092011201320152017\end{array}$ & \\
\hline
\end{tabular}

Data sources: web of science.

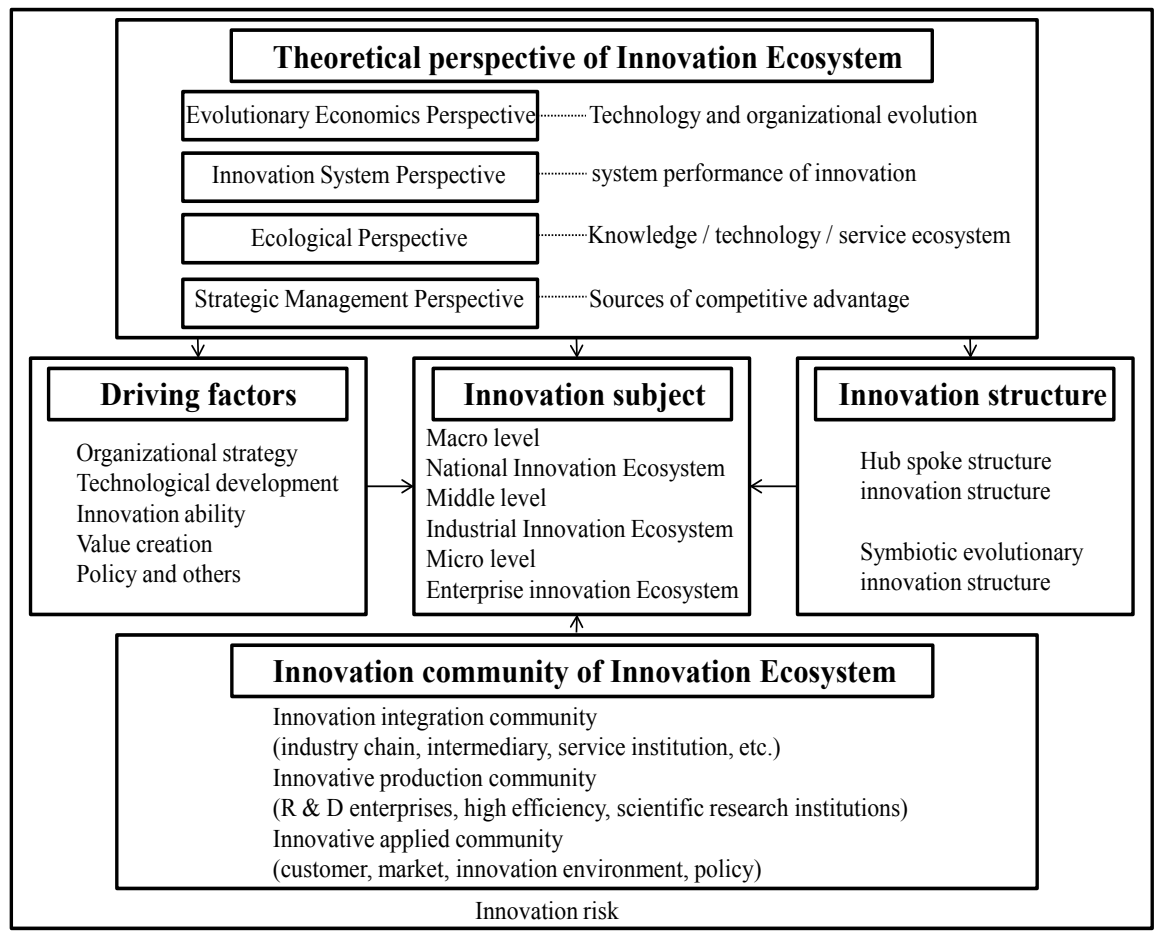

Figure 11. Theoretical framework of innovation ecosystem.

innovation system based on the characteristics of innovation system; the perspective of ecology and the perspective of strategic management. According to 
the innovation subject of innovation ecosystem, the innovation subject is divided from macro, middle and micro levels. According to the driving factors of different innovation subject, the development of innovation structure and innovation community is also different. The specific content is shown in Figure 11.

Based on the theoretical framework of innovation ecosystem, this paper analyzes the multi-path node literature from the perspective of innovation, driving factors, innovation subject, innovation structure, innovation community and innovation risk. Firstly, from the perspective of innovation, the review of innovation ecosystem based on evolutionary economics mainly explores the evolution and development of technology and organization. The innovative perspective of early research is mainly from the perspective of innovation system and strategic management. After 2015, the research perspective of scholars has changed to the ecological perspective, which means the perspective of ecology to study the interaction among technology, knowledge process and economic society. In terms of driving factors, the driving factors have changed from organizational strategy driver to diversification drivers, such as innovation ability driving, technology development driving, policy driving and so on, finally to value driving in recent years. The main subject of innovation is still concentrated on the industry innovation ecosystem. Some of the research objects in the key literature are targeted at certain industries, such as pharmaceutical industry, payment industry, digital music industry, mobile platform industry and so on. Another is the evaluation of the whole industry. This paper classifies the two types into the industry innovation ecosystem, because it pays more attention to the integration and utilization of resources on the platform among industries. Secondly, the innovation structure evolves from the hub spoke development in the early stage, that is, from the joint development of core enterprises (focus enterprises) to the symbiotic evolutionary innovation structure of enterprises in the later stage. At the same time, innovation community has been taking innovation integration community as the main link of the industrial chain integration. In recent years, scholars have been more in-depth study, focusing on innovation production community and innovation applied community. Think from aspects of the upstream and downstream of innovation ecological ecosystem. Finally, the problem of innovation risk is also an important factor affecting the development of innovation ecosystem. Some of the failure of innovation ecosystem is caused by the trust crisis of members in innovation risk. Therefore, scholars have strengthened the research on this basic factor. As far as the key literature is concerned, the research of scholars in 2013 will be more involved in innovation risk. In the following years, the innovation risk of articles will be more integrated into the articles rather than independently studied.

\section{Conclusions, Limitations and Future Research}

In this paper, the scientific measurement method is used to systematically sort out the theme development of innovation ecosystem and the following conclu- 
sions are drawn. Firstly, based on descriptive statistics, innovative ecosystems, as an emerging field, are developing rapidly and will be further expanded in the foreseeable future. Throughout the process, scholars (Adner R, Kapoor R, Gawer A, Iansiti Marco) have made outstanding contribution to the development of innovative ecosystems, leading the direction of development in this field. Based on the main path approach, this paper finds that as a whole, innovative ecosystems are widely adapted to different disciplines, and they are not mature and are expanding. However, due to the limitation of the method of calculating the path, some important academic opinions published by scholars such as Moore and Levin have been omitted, so the multi-path method is further extended to refine. This paper divides the development of innovation ecosystem into three parts: business ecosystem, technology ecosystem and service ecosystem. Based on the path analysis, this paper constructs the theoretical framework of innovation ecosystem, and finds that the article in the field of innovation ecosystem develops from commercial innovation ecosystem to service innovation ecosystem. From the perspective of early strategic management and innovation system to the perspective of multi-disciplinary ecology, value co-creation has gradually become the main achieve goal to promote the development of innovation ecosystem.

In the future, the research of innovative ecosystem will involve more disciplines and fields. Innovation ecosystem will pay more attention to the value creation of consumers, such as service ecosystem. For example, from a macro perspective, the service ecosystem believes that all economic and social participants are an important part of value creation. At the same time, the collection and effective processing of information data will become an important foundation for building an innovative ecosystem. However, there are still some shortcomings in the research of innovation ecosystem. Most of the nodal literature on the main path is case studies. Case studies can make us understand the application of innovation ecosystem more clearly, but the comparability of case studies is not strong, and the theoretical expansion is insufficient. In the future, the study of innovation ecosystem should be more in-depth, to open the internal black box of the effective construction of innovation ecosystem, and reveal the core of the internal operation and value creation in innovation ecosystem. Finally, through the open-ended analysis of the innovation ecosystem, we provide a set of system mechanism for innovation development. Use this mechanism in the Chinese market environment in order to form an innovation ecosystem with Chinese characteristics, thereby enhancing the core competitiveness and commercial value of enterprises.

\section{Acknowledgements}

The study is supported by the National Natural Science Foundation of China (Grant \#71473086, 71233003) and Key Projects of Philosophy and Social Sciences Research, Ministry of education (Grant \#12JZD042). The authors are 
very grateful for the valuable comments and suggestions from the Reviewers and Editors of the journal, which significantly improved the quality and readability of the paper.

\section{Conflicts of Interest}

The authors declare no conflicts of interest regarding the publication of this paper.

\section{References}

[1] Watanabe, C. and Fukud,a K. (2006) National Innovation Ecosystems: The Similarity and Disparity of Japan-US Technology Policy Systems toward a Service Oriented Economy. Journal of Services Research, 6, 159-186.

[2] National Research Council (2012) Rising to the Challenge: U.S. Innovation Policy for the Global Economy. The National Academies Press, Washington DC.

[3] McCarthy, D.J., Puffer, S.M. and Graham, L.R. (2014) Emerging Innovation in Emerging Economies: Can Institutional Reforms Help Russia Break through Its Historical Barriers. Thunderbird International Business Review, 56, 243-260. https://doi.org/10.1002/tie.21619

[4] Liu, J.S., Lu, L.Y.Y., Lu, W.M., et al. (2013) Data Envelopment Analysis 1978-2010: A Citation-Based Literature Survey. Omega, 41, 3-15. https://doi.org/10.1016/j.omega.2010.12.006

[5] Hummon, N.P. and Dereian P. (1989) Connectivity in a Citation Network: The Development of DNA Theory. Social Networks, 11, 39-63. https://doi.org/10.1016/0378-8733(89)90017-8

[6] Batagelj, V. (2003) Efficient Algorithms for Citation Network Analysis. Computer Science, arXiv:cs/0309023v1.

[7] Fontana, R., Nuvolari, A. and Verspagen, B. (2009) Mapping Technological Trajectories as Patent Citation Networks. An Application to Data Communication Standards. Economics of Innovation \& New Technology, 18, 311-336. https://doi.org/10.1080/10438590801969073

[8] Borodin, A., Roberts, G.O., Rosenthal, J.S., et al. (2002) Finding Authorities and Hubs from Link Structures on the World Wide Web. WWW10, Hong Kong, 1-5 May 2001.

[9] Meyer, P.S., Yung, J.W. and Ausubel, J.H. (1999) A Primer on Logistic Growth and Substitution: The Mathematics of the Loglet Lab Software. Technological Forecasting \& Social Change, 61, 247-271. https://doi.org/10.1016/S0040-1625(99)00021-9

[10] Hirsch, J.E. (2005) An Index to Quantify an Individual's Scientific Research Output. Proceedings of the National Academy of Sciences of the United States of America, 102, 16569-16572. https://doi.org/10.1073/pnas.0507655102

[11] Ding, C.H.Q., Zha, H., He, X., et al. (2004) Link Analysis: Hubs and Authorities on the World Wide Web. Siam Review, 46, 256-268.

https://doi.org/10.1137/S0036144501389218

[12] Lawrence, S., Bollacker, K. and Giles, C.L. (1999) Indexing and Retrieval of Scientific Literature. Eighth International Conference on Information and Knowledge Management, Kansas City, 2-6 November 1999, 139-146.

[13] Teece, D.J. (2010) Explicating Dynamic Capabilities: The Nature and Microfoundations of (Sustainable) Enterprise Performance. Strategic Management Journal, 28, 
1319-1350. https://doi.org/10.1002/smj.640

[14] Lucio-Arias, D. and Leydesdorff, L. (2008) Main-Path Analysis and Path-Dependent Transitions in HistCite ${ }^{\text {TM}}$-Based Historiograms. Journal of the Association for Information Science and Technology, 59, 1948-1962. https://doi.org/10.1002/asi.20903

[15] Sun, F. and Zhu, L. (2012) Citation Genetic Genealogy: A Novel Insight for Citation Analysis in Scientific Literature. Scientometrics, 91, 577-589. https://doi.org/10.1007/s11192-011-0588-2

[16] Adner, R. (2006) Match Your Innovation Strategy to Your Innovation Ecosystem. Harvard Business Review, 84, 98.

[17] Adner, R. and Kapoor, R. (2010) Value Creation in Innovation Ecosystems: How the Structure of Technological Interdependence Affects Firm Performance in New Technology Generations. Strategic Management Journal, 31, 306-333. https://doi.org/10.1002/smj.821

[18] Adner, R. and Kapoor, R. (2016) Innovation Ecosystems and the Pace of Substitution: Re-Examining Technology S-Curves. Strategic Management Journal, 37, 625-648. https://doi.org/10.1002/smj.2363

[19] Adner, R. (2017) Ecosystem as Structure: An Actionable Construct for Strategy. Journal of Management, 43, 39-58. https://doi.org/10.1177/0149206316678451

[20] Dedehayir, O. and Mäkinen, S.J. (2011) Measuring Industry Clockspeed in the Systemic Industry Context. Technovation, 31, 627-637. https://doi.org/10.1016/j.technovation.2011.07.008

[21] Kapoor, R. and Lee, J.M. (2013) Coordinating and Competing in Ecosystems: How Organizational Forms Shape New Technology Investments. Strategic Management Journal, 34, 274-296. https://doi.org/10.1002/smj.2010

[22] Li, J.F. and Garnsey, E. (2014) Policy-Driven Ecosystems for New Vaccine Development. Technovation, 34, 762-772. https://doi.org/10.1016/j.technovation.2014.07.002

[23] Gawer, A. and Cusumano, M.A. (2014) Industry Platforms and Ecosystem Innovation. Journal of Product Innovation Management, 31, 417-433. https://doi.org/10.1111/jpim.12105

[24] Gawer, A. and Cusumano, M.A. (2008) How Companies Become Platform Leaders. Mit Sloan Management Review, 49, 28-35.

[25] Horn, P.M. (2005) The Changing Nature of Innovation. Research Technology Management, 48, 28-31. https://doi.org/10.1080/08956308.2005.11657345

[26] Li, Y.R. (2009) The Technological Roadmap of Cisco’s Business Ecosystem. Technovation, 29, 379-386. https://doi.org/10.1016/j.technovation.2009.01.007

[27] Adomavicius, G., Bockstedt, J.C., Gupta, A., et al. (2008) Making Sense of Technology Trends in the Information Technology Landscape: A Design Science Approach. Mis Quarterly, 32, 779-809. https://doi.org/10.2307/25148872

[28] Ceccagnoli, M., Forman, C., Huang, P. and Wu, D.J. (2011) Cocreation of Value in a Platform Ecosystem: The Case of Enterprise Software. Mis Quarterly, 36, 263-290. https://doi.org/10.2307/41410417

[29] Storbacka, K., Brodie, R.J., Böhmann, T., et al. (2016) Actor Engagement as a Microfoundation for Value Co-Creation. Journal of Business Research, 69, 3008-3017. https://doi.org/10.1016/j.jbusres.2016.02.034

[30] Lusch, R.F., Vargo, S.L. and Gustafsson, A. (2016) Fostering a Trans-Disciplinary Perspectives of Service Ecosystems. Journal of Business Research, 69, 2957-2963. 
https://doi.org/10.1016/j.jbusres.2016.02.028

[31] Iansiti, M. and Levien, R. (2004) Strategy as Ecology. Harvard Business Review, 82, 68.

[32] Basole, R.C. (2009) Visualization of Interfirm Relations in a Converging Mobile Ecosystem. Journal of Information Technology, 24, 144-159.

https://doi.org/10.1057/jit.2008.34 